\title{
FAILURE ANALYSIS OF ANCHORING SYSTEM OF A CIRCULATING FLUIDIZED BED BOILER
}

\author{
${ }^{1}$ Agata DUDEK, ${ }^{2}$ Jerzy CUGOWSKI \\ 1,2 Czestochowa University of Technology, Institute for Material Engineering, Faculty of Processing \\ Engineering and Applied Physics, Czestochowa, Poland, EU, dudek@wip.pcz.pl \\ 2 Reffording Sp. z o.o. ul. Józefa Poniatowskiego 171/20, Czeladź, Poland, EU
}

https://doi.org/10.37904/metal.2020.3509

\begin{abstract}
The combustion of fuels plays an important role in the field of industry and power engineering. Circulating fluidized bed combustion (CFBC) is a clean technology and also it is a convenient method of energy production from a wide range of fuels. The present paper reports the results of the authors' investigation focused on the analysis of heat resistant steel samples from one of the Polish circulating fluidized bed boilers. The anchors were degraded during boiler operation and lost their mechanical durability. To determine the reasons for anchors degradation the materials were subjected to microstructural analysis using a light microscope, scanning microscopy Joel JSM 5400 equipped with EDS. In the case of the investigated anchor samples, the formation of a large number of hard and chromium-rich intrusions was determined. The reason for material problems as incorrect positioning of the anchors in the refractory material was determined.
\end{abstract}

Keywords: Circulating fluidized combustion, anchor failure

\section{INTRODUCTION}

Recently, more attention is put to the fluidized bed combustion technology [1] mainly due to its numerous advantages, such as the ability to accept various fuels, low emission of NOx, and high combustion efficiency. There are three basic types of fluidized bed combustion boilers (see Figure 1):

- $\quad$ Bubbling fluidized bed boilers with atmospheric pressure, A-BFB or BFB,

- $\quad$ Pressurized bubbling fluidized bed boilers, PBFB,

- $\quad$ Circulating fluidized bed boilers with atmospheric pressure, A-CFB or CFB, and pressurized circulating fluidized bed boilers, PCFB.

In the CFB boiler, the combustion process takes place in an oven where the temperature is maintained at around $850-860^{\circ}$. In the fluidized bed boiler, the refractory materials are used to minimize wall erosion, isolate uncooled elements and help protect steel elements. Refractory materials are used in: the bottom wall of the combustion chamber, the roof of the combustion chamber outlet, loop seals, start-up, channel burner, cyclone, and external fluidized bed heat exchangers. These materials are in place thanks to anchors welded to the ribs of the membrane wall. The main task of the anchoring system is to provide high mechanical durability of the refractory, which is responsible for high protection against erosion and corrosion. The anchor failures easily leads to damage to the refractory wall cladding [2]. Failure of the anchoring system can have several causes, e.g. improper anchor design, improper use of material, incorrect parameters boiler, not enough anchors per square foot of refractory. Failures also result from rapid or incorrect heating and cooling of the refractory material during boiler operation. This causes the irregular expansion and contraction of the refractory material, which results in cracking or flaking. Anchor system failure on walls and roofs will result in the weight of the refractory to pull itself away and result ultimately in cracking and collapse. These failures may result from the irregular thickness of the material, the improper use of expansion joints, or the improper use of refractory layers [3]. 


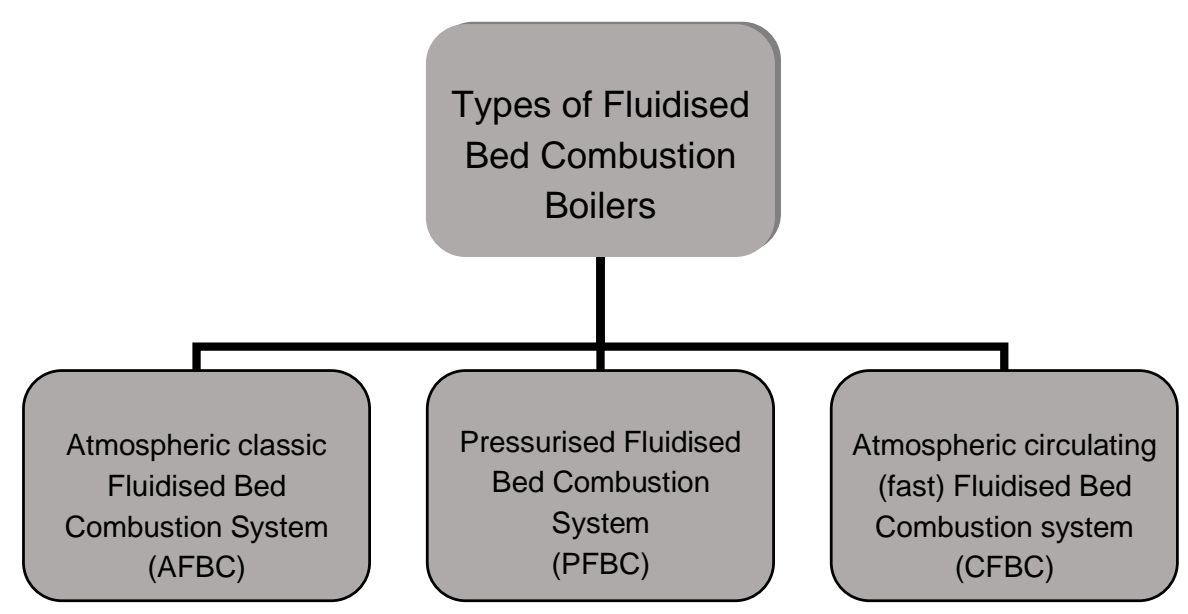

Figure 1 Basic types of fluidised bed combustion boilers

The anchors must be made of heat and corrosion-resistant materials [4-6] because, in CFB boilers, it can be exposed to high temperatures during equipment operation. If carbon steel is used in this case, the anchor will certainly fail due to harmful microstructure changes and accelerated corrosion.

The obtained results may be also useful in other apparatus parts working in aggressive, sometime hightemperature environments e.g. biotechnology [7-9] or produced at high-temperature impulse impacts e.g. laser machining [10-12]. The obtained datasets may inspirational as a source of reliable data for many computational analysis methods e.g. image analysis [13,14], bootstrap numerical simulations $[15,16]$ and - especially for industrial developments - decision support systems [17] and possible failure analyses [18-20], in the context of lean management [21] and sustainable development [22].

\section{MATERIALS AND METHODS}

The tested anchors were obtained from one of the Polish CFB 75 MWe coal boilers. An example and shape of anchors is seen in Figure 2.
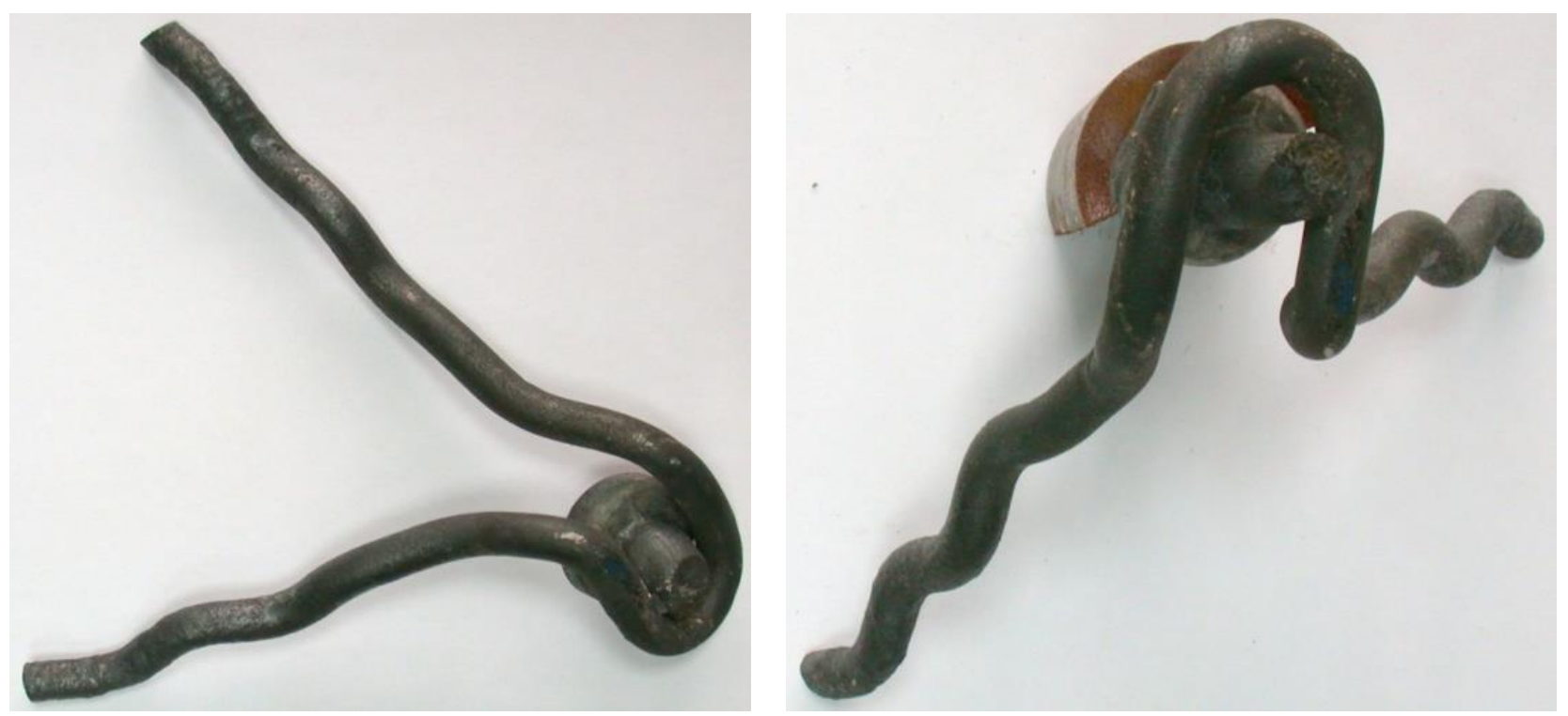

Figure 2 Macroscopic appearance of the investigated anchor samples 
The refractory material was damaged because all anchors lost their mechanical properties and came off the membrane wall. The failure of the anchor system on the walls caused the weight of the refractory material to break away and cracks were formed.

To analyse the causes of cracking and damage to anchors, several analysis were performed. Macroscopic, microscopic, and chemical analysis of the anchoring system was performed using an Axiovert 25 optical microscope from Carl Zeiss, a JEOL JSM-6610LV scanning microscope with a LaB6 cathode.

\section{RESULTS AND DISCUSSION}

Fractography of fractures of anchor elements obtained by the scanning microscope is shown in Figure 3 .
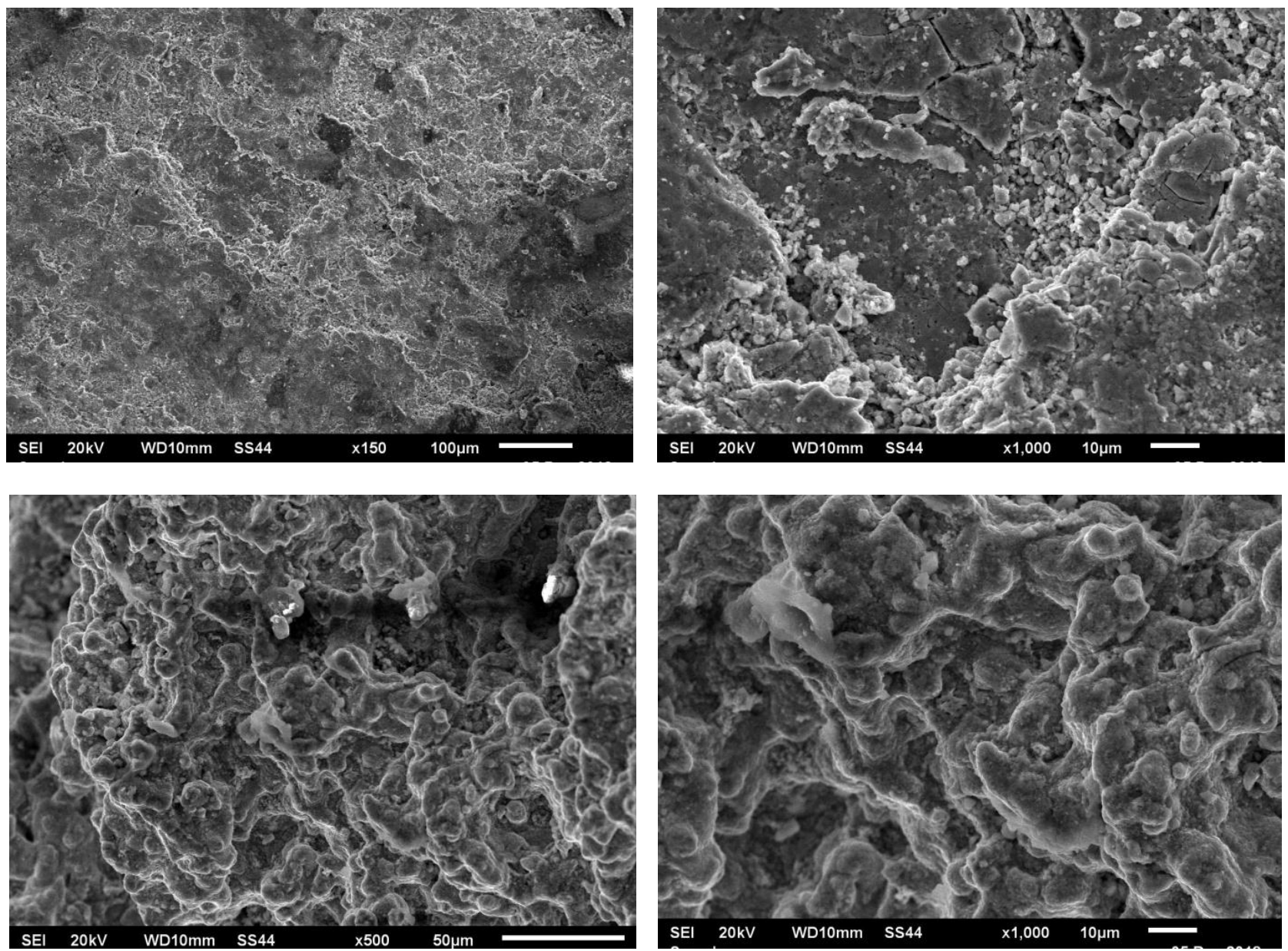

Figure 3 The cross-section view of the damaged anchor

Fractographic studies confirmed macroscopic observations. Sediment formed as a result of boiler operation was revealed on the fracture surfaces. The fractures showed features of brittle fracture.

In the next stage of research, metallographic specimens were made, which were etched to observe the microstructure of the steel from which the anchors were made. The microstructure of steel in the places of cracking of the anchors is shown in Figure 4 (light microscope - LM) and Figure 5 (scanning microscopeSEM).

Austenitic steel structure with very numerous precipitations of the second phase located mainly on grain boundaries was revealed in the elements which broke in a brittle manner without prior narrowing of the material as well as in the case of the element that underwent plastic deformation before cracking. 

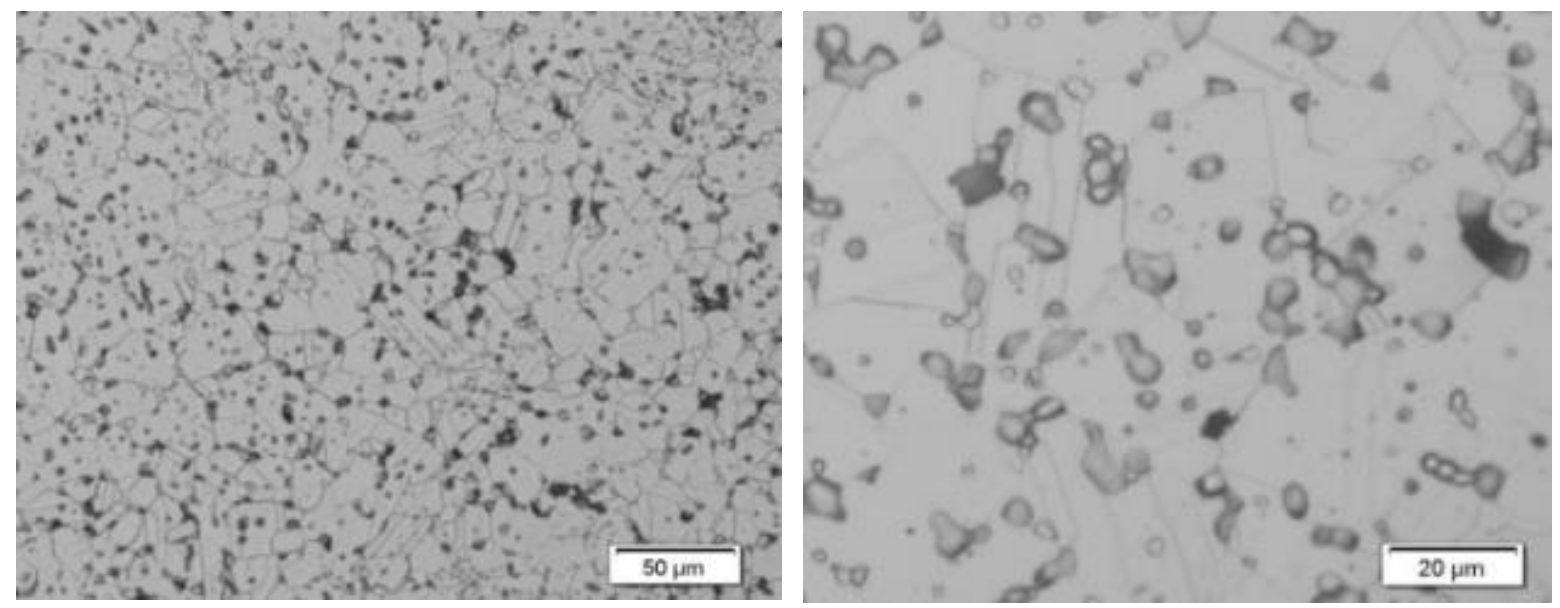

Figure 4 Microstructure of the damaged anchor - LM - different magnifaciations
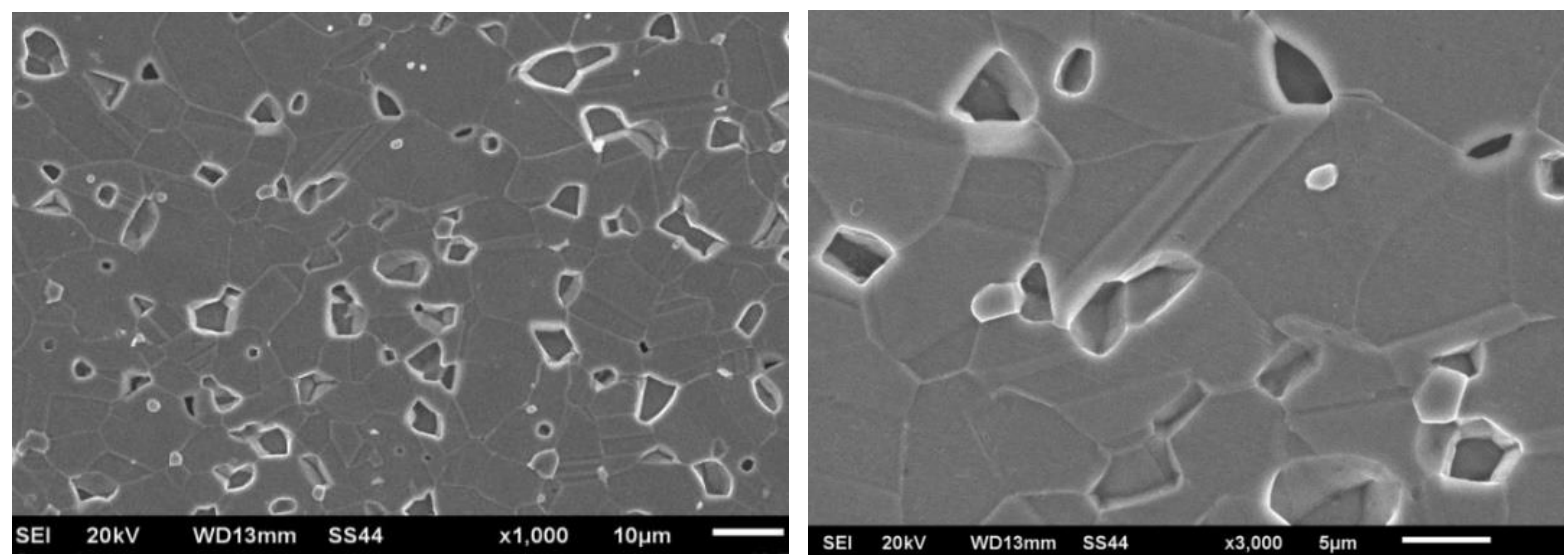

Figure 5 Microstructure of the damaged anchor (less and greater magnification) - SEM

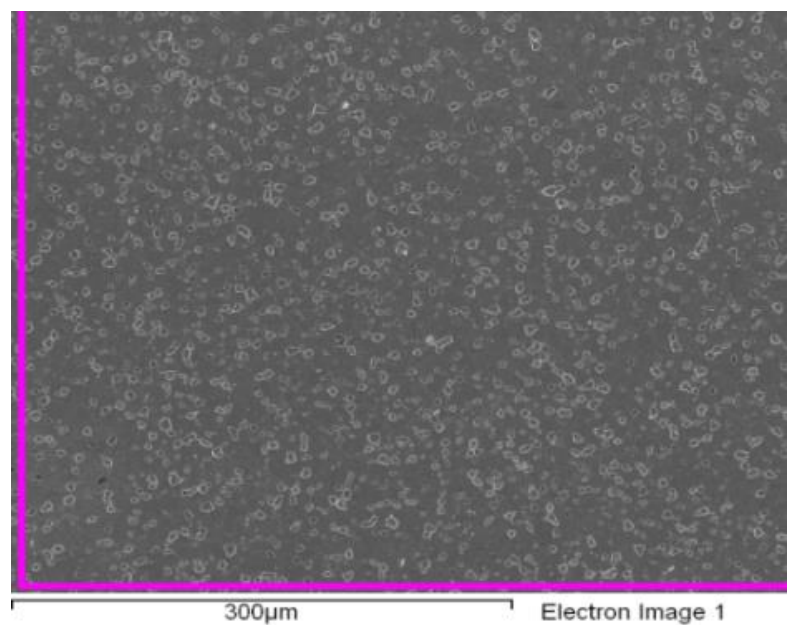

$\begin{array}{ccc}\text { Element } & \text { Weight (\%) } & \text { Atomic (\%) } \\ \text { C K } & 2.58 & 10.84 \\ \text { Si K } & 0.47 & 0.85 \\ \text { Cr K } & 23.14 & 22.45 \\ \text { Mn K } & 2.32 & 2.13 \\ \text { Fe K } & 52.49 & 47.41 \\ \text { Ni K } & 18.99 & 16.32 \\ \text { Total } & 100.00 & \end{array}$

Figure 6 Chemical composition of the samples

Figure 6 and Figure 7 show the results obtained by EDS analysis, performed in the damaged anchor. Analysis of the chemical composition of the samples indicated that the steel anchors are made of heat-resistant stainless steel AISI 310 (X15CrNiSi25-20). The steel has an austenitic structure and is designed to work in particularly high temperatures according to PN-71 / H-86022, EN 10095. Analysis of the breakthrough revealed an increased number of sigma precipitates in the damaged anchors. Those sigma precipitates contributed 
directly to the formation of cracks and damage of the anchors since the sigma phase is an intermetallic phase that is hard and chromium-rich and its presence in the steel structure causes the significant drop of the resistance of the steel against impacts or mechanical loadings.

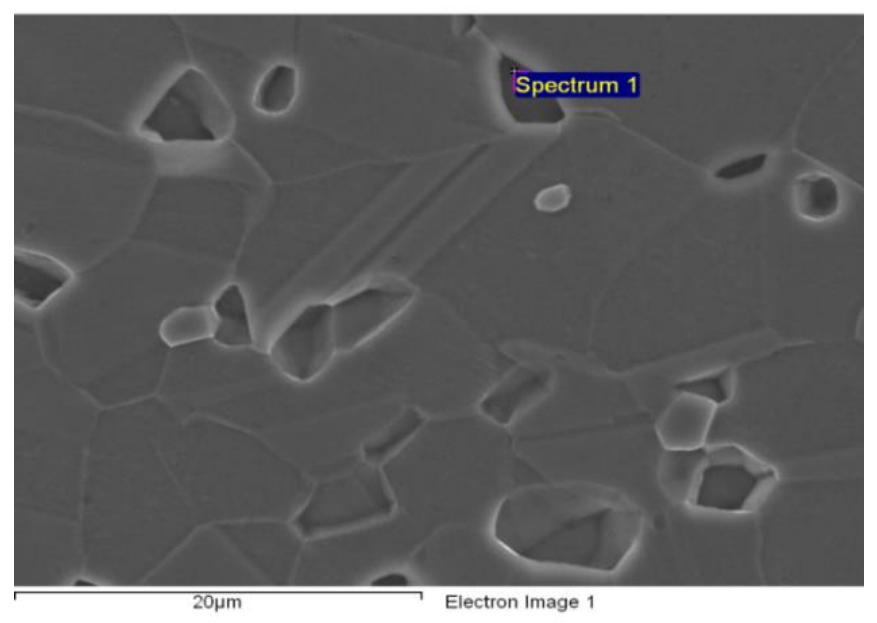

$\begin{array}{ccc}\text { Element } & \text { Weight (\%) } & \text { Atomic (\%) } \\ \text { Si K } & 0.18 & 0.34 \\ \text { Cr K } & 43.00 & 44.84 \\ \text { Mn K } & 1.73 & 1.70 \\ \text { Fe K } & 47.20 & 45.83 \\ \text { Ni K } & 7.89 & 7.29 \\ \text { Total } & 100.00 & \end{array}$

Figure 7 Chemical composition of the samples

\section{CONCLUSIONS}

The microstructure analysis of the anchor elements revealed an austenitic structure and numerous precipitations of the sigma $\sigma-\mathrm{FeCr}$ fragile phase located mainly on the austenite grain boundaries, whose presence was confirmed by microstructure and chemical composition studies. Long-term heating of AISI 310 steel (in the temperature range $500-900^{\circ} \mathrm{C}$ ) is not recommended due to the risk of increased brittleness and the formation of a hard and brittle phase of intermetallic sigma. It was found that the reason for the anchors cracking was the way they were placed in the cladding layers. The anchor pin was placed in a layer of heatresistant concrete and was subjected to loads and deformations. This was related to, among others, thermal expansion of all materials during boiler operation.

In further investigation, the more detailed methods will be used, among others surface layer scanning and analysis [23], analysis of materials additives [24] and more sophisticated methods of data analysis [25-28].

\section{REFERENCES}

[1] LIU, A., SHI, Y., ZHONG, W. , YU, A. Co-firing of coal and biomass in oxy-fuel fluidized bed for CO2 capture: A review of recent advances. Chinese Journal of Chemical Engineering. 2019. vol. 27, pp. 2261-2272.

[2] SINGH, A.A., SHARMA, V.A., MITTAL, S.A., PANDEY, G.A., MUDGAL, D.A.B., GUPTA, P. An overview of problems and solutions for components subjected to fireside of boilers. Int. J. Ind. Chem. 2018. vol. 9, pp. 1-15.

[3] PRABIR, B. Circulating Fluidized Bed Boilers: Design, Operation and Maintenance, Springer, 2015.

[4] SZABRACKI, P. and LIPINSKI, T. Influence of sigma phase precipitation on the intergranular corrosion resistance of X2CrNiMoN25-7-4 super duplex stainless steel. In METAL 2014: 23rd Int. Conf. on Metallurgy and Materials. Ostrava, TANGER, 2014, pp. 476-481.

[5] ULEWICZ, R., SZATANIAK, P. and NOVY, F. Fatigue properties of wear resistant martensitic steel. In METAL 2014: $23^{\text {rd }}$ Int. Conf. on Metallurgy and Materials. Ostrava, TANGER, 2014, pp. 784-789.

[6] KLIMECKA-TATAR, D. Powder Surface Modification as a Method of Corrosion Rate Limitation of the Magnetic RE-M-B Composite in an Acid Medium with Different pH. Materials Research Proc. 2018. vol. 5, pp.231-236.

[7] SKRZYPCZAK-PIETRASZEK, E., REISS, K., ZMUDZKI, P., PIETRASZEK, J. Enhanced accumulation of harpagide and 8-O-acetyl-harpagide in Melittis melissophyllum L. agitated shoot cultures analyzed by UPLCMS/MS. PLOS One. 2018. vol. 13, art. e0202556. 
[8] SKRZYPCZAK-PIETRASZEK, E., PISKA, K., PIETRASZEK, J. Enhanced production of the pharmaceutically important polyphenolic compounds in Vitex agnus castus $\mathrm{L}$. shoot cultures by precursor feeding strategy. Engineering in Life Sciences. 2018. vol. 18, pp.287-297.

[9] SKRZYPCZAK-PIETRASZEK, E., URBANSKA, A., ZMUDZKI, P., PIETRASZEK, J. Elicitation with methyl jasmonate combined with cultivation in the Plantform ${ }^{T M}$ temporary immersion bioreactor highly increases the accumulation of selected centellosides and phenolics in Centella asiatica (L.) Urban shoot culture. Engineering in Life Sciences. 2019. vol. 19, pp.931-943.

[10] RADEK, N., BARTKOWIAK, K. Laser treatment of Cu-Mo Electro-Spark Deposited Coatings. Physics Procedia. 2011. vol. 12, pp. 499-505.

[11] RADEK, N., BARTKOWIAK, K. Laser treatment of electro-spark coatings deposited in the carbon steel substrate with using nanostructured WC-Cu electrodes. Physics Procedia. 2012. vol. 39, pp. 295-301.

[12] GADEK-MOSZCZAK, A., RADEK, N., WRONSKI, S., TARASIUK, J. Application the 3D Image Analysis Techniques for Assessment the Quality of Material Surface Layer Before and After Laser Treatment. Advanced Materials Research-Switz. 2014. vol. 874, pp.133-138.

[13] GADEK-MOSZCZAK, A. History of stereology. Image Analysis \& Stereology. 2017. vol. 36, pp. 151-152.

[14] GADEK-MOSZCZAK, A., MATUSIEWIC, P. Polish stereology - a historical review. Image Analysis \& Stereology. 2017. vol. 36, pp. 207-221.

[15] PIETRASZEK, J., GADEK-MOSZCZAK, A. The Smooth Bootstrap Approach to the Distribution of a Shape in the Ferritic Stainless Steel AISI 434L Powders. Solid State Phenomena. 2012, vol. 197, pp. 162-167.

[16] GADEK-MOSZCZAK, A., PIETASZEK, J., JASIEWICZ, B., SIKORSKA, S., WOJNAR, L. The Bootstrap Approach to the Comparison of Two Methods Applied to the Evaluation of the Growth Index in the Analysis of the Digital Xray Image of a Bone Regenerate. New Trends in Comp. Collective Intell. 2015. vol. 572, pp.127-136.

[17] PACANA, A., PASTERNAK-MALICKA, M., ZAWADA. M., RADON-CHOLEWA, A. Decision support in the production of packaging films by cost-quality analysis. Przemysl Chemiczny. 2016. vol. 95, pp. 1042-1044.

[18] SYGUT, P., KLIMECKA-TATAR, D., BORKOWSKI, S. Theoretical analysis of the influence of longitudinal stress changes on band dimensions during continuous rolling process. Arch. Metall. Mater. 2016. vol. 61, pp.183-188.

[19] BORKOWSKI, S., ULEWICZ, R., SELEJDAK, J., KONSTANCIAK, M., KLIMECKA-TATAR, D. The use of $3 \times 3$ matrix to evaluation of ribbed wire manufacturing technology. In METAL 2012: 21st Int. Conf. on Metallurgy and Materials. Ostrava: TANGER, 2012, pp. 1722-1728.

[20] INGALDI, M. and ULEWICZ, R. Evaluation of Quality of the e-Commerce Service. International Journal of Ambient Computing and Intelligence. 2018. vol. 9, pp. 55-66.

[21] MASZKE, A., DWORNICKA, R. and ULEWICZ, R. Problems in the implementation of the lean concept at a steel works - Case study. MATEC Web of Conferences. 2018. vol. 183, art. 01014.

[22] ULEWICZ, R. and BLASKOVA, M. Sustainable development and knowledge management from the stakeholders' point of view. Polish Journal of Management Studies. 2018. vol. 18, pp. 363-374.

[23] KLIMECKA-TATAR, D., BORKOWSKI, S., SYGUT, P. The kinetics of Ti-1Al-1Mn alloy thermal oxidation and characteristic of oxide layer. Arch. Metall. Mater. 2015. vol. 60, pp. 735-38.

[24] LIPINSKI, T. Double modification of AISi9Mg alloy with boron, titanium and strontium. Arch. Metall. Mater. 2015, vol. 60, pp. 2415-2419.

[25] STYRYLSKA, T., PIETRASZEK, J. Numerical modeling of non-steady-state temperature-fields with supplementary data. ZAMM-Z. Angew. Math. Mech. 1992. vol. 72, pp. T537-T539.

[26] PIETRASZEK, J. Response surface methodology at irregular grids based on Voronoi scheme with neural network approximator. In: Rutkowski L., Kacprzyk J. (eds) Neural Networks and Soft Computing. Advances in Soft Computing, vol 19. Physica, Heidelberg: 2003, pp. 250-255.

[27] PACANA, A., BEDNAROVA, L., LIBERKO, I., WOZNY, A. Effect of selected production factors of the stretch film on its extensibility. Przemysl Chemiczny. 2014. Vol. 93, pp. 1139-1140.

[28] PACANA, A., RADON-CHOLEWA, A., PACANA, J., WOZNY, A. The study of stickiness of packaging film by Shainin method. Przemysl Chemiczny. 2015. vol. 94, pp. 1334-1336. 